\title{
A Sliding Mode Controller for a Three Phase Induction Motor
}

\author{
Eman El-Gendy \\ Demonstrator at \\ Computers and \\ Systems \\ Engineering, \\ Mansoura University, \\ Egypt
}

\author{
Abdelhameed F. \\ Ibrahim \\ Lecturer at \\ Computers and \\ Systems \\ Engineering, \\ Mansoura University, \\ Egypt
}

\author{
Sabry F. Saraya \\ Assistant professor \\ at Computers and \\ Systems Engineering \\ Mansoura \\ University, Egypt
}

\author{
Fayez. F. G. \\ Areed \\ Professor at \\ Computers and \\ System Engineering, \\ Mansoura University, \\ Egypt
}

\begin{abstract}
In this paper, a sliding mode controller (SMC) is designed to control the speed of an induction motor fed by three phase voltage source inverter based on space vector pulse width modulation (SVPWM) technique. The sliding mode controller is a nonlinear controller. The space vector pulse width modulation technique is advanced pulse width modulation (PWM) technique. The proposed scheme enables us to adjust the speed of the motor by controlling the frequency and amplitude of the stator voltage; the ratio of the stator voltage to the frequency should be kept constant. Simulation results show the validation of the proposed scheme.
\end{abstract}

\section{Keywords}

Sliding mode controller, induction motor, space vector pulse width modulation

\section{INTRODUCTION}

Induction motors are used in many applications such as motion control, robotics, and automotive control. $[1,2]$. The squirrel-cage induction motor has been widely used in many control systems. It has many advantages, such as simple and rugged structure and low cost. However, induction motors also have speed control problems [1].

Many control methods have been used for the induction motor [3-10]. The space vector pulse width modulation (SVPWM) method is an advanced PWM method for variable frequency drive applications [11]. Space vector modulation is based on the representation of three phase voltages as space vectors. $[12,13]$.

Classical control systems like PI (proportional-integral) control have been used for the speed control of induction machines. The main drawbacks of classical PI controllers are their large overshoot and excessive settling time. To face these problems, sliding mode control has recently been applied to the control of electrical drive systems. A sliding mode controller (SMC) is a nonlinear, high speed switching, feedback control strategy that provides an effective and robust approach for controlling nonlinear plants [14-16]. However, the SMC easily produces a chattering phenomenon due to its discontinuous switching control.

In this paper, a sliding mode controller is designed to control the speed of an induction motor fed by three phase voltage source inverter based on space vector pulse width modulation technique. Simulation results show the validation of the proposed scheme.

The paper is organized as follows: Section 2, presents the space vector pulse width modulation and the sliding mode controller. The sliding mode controller based design is shown in Section 3. In section 4, simulation results are given to validate the proposed approach. Section 5 gives a comparative study. This paper is concluded in Section 6.

\section{SLIDING MODE CONTROLLER}

The motor speed $\omega_{\mathrm{r}}$ should track a specific reference speed $\omega_{\mathrm{r}}{ }^{*}$ in the presence of load torque and noise. The system is controlled in such a way that the error $\mathrm{e}=\omega_{\mathrm{r}}{ }^{*}-\omega_{\mathrm{r}}$ and its rate of change é always move towards a sliding surface. The sliding surface is defined in the state space by the equation [18]:

$$
\mathrm{s}(\mathrm{e}, \dot{\mathrm{e}}, \mathrm{t})=0
$$

where: the sliding variable $s$ is:

$$
\mathrm{s}=\dot{\mathrm{e}}+\lambda \mathrm{e}
$$

where: $\lambda$ is a positive constant that depends on the bandwidth of the system.

The problem is to remain on the sliding surface for all the time, and the sliding variable $s$ is kept at zero. The condition of sliding mode is :

$$
\frac{1}{2} \frac{\mathrm{d}}{\mathrm{dt}} \mathrm{s}^{2}=\mathrm{s} \dot{\mathrm{s}} \leq-\eta|\mathrm{s}|
$$

where: $\eta$ is a positive constant.

\section{PROPOSED SLIDING MODE CONTROLLER SCHEME}

The flow chart of the sliding mode control process is represented in Figure 1. It illustrates that the sliding mode control is performed by reading the value of actual speed and comparing it to the reference speed to generate an error signal. This error signal and the derivative of error are used to determine the switching surface and the state of the system must remain on the sliding surface. The controller then generates the 6 PWM signals for inverter and compares the error value e to a set value $\varepsilon_{0}$. If the error is less than this value, the error value is printed and the control process stops, otherwise the process is repeated to an acceptable error value. 


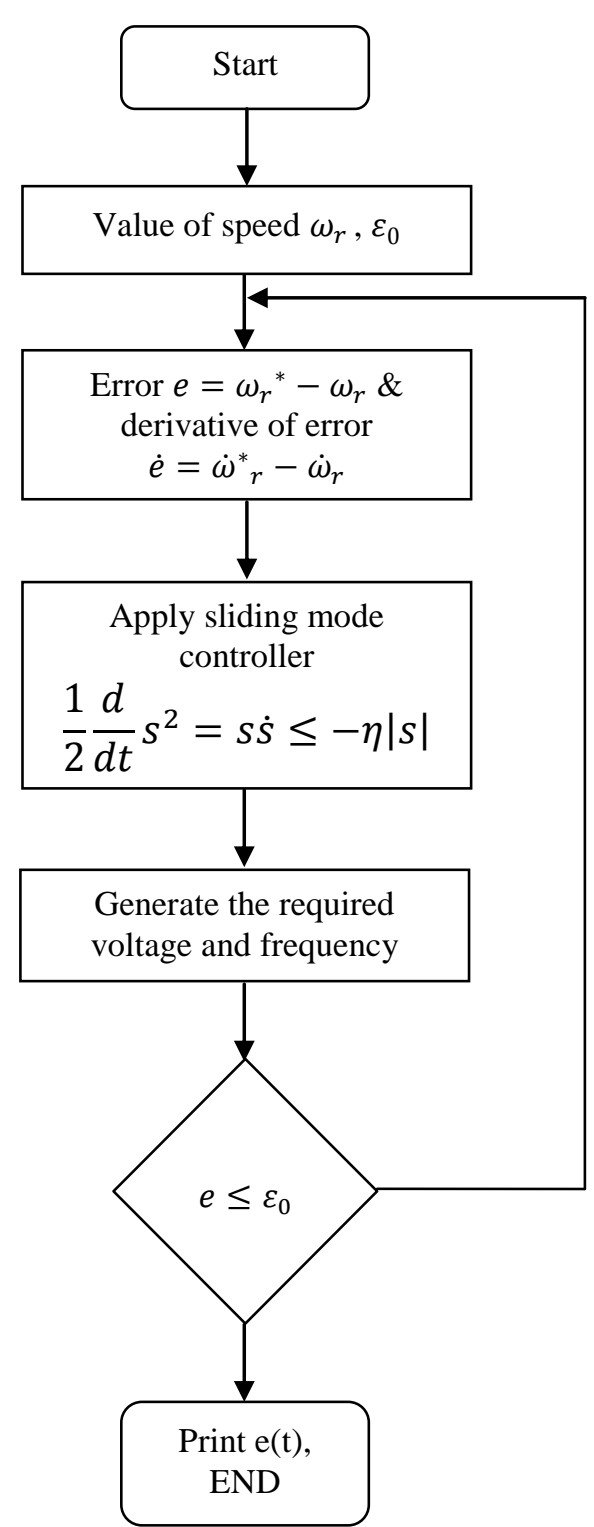

Fig. 1: Flow chart of the sliding mode control process.

\section{SIMULATION RESULTS AND ANALYSIS}

The speed is a step function with initial value of $500 \mathrm{rpm}$ and final value of $1200 \mathrm{rpm}$. There is no load torque.

\subsection{Using PI Controller}

For the speed shown in Fig. 2, the rise time is $1.2526 \mathrm{sec}$ and the settling time is $1.405 \mathrm{sec}$. The maximum overshoot is 21 rpm. The peak time is $0.935 \mathrm{sec}$, and the delay time is 1.06 sec. For the torque shown in Fig. 3, the ratio of ripples varies as follows:

- From $0 \mathrm{sec}$ to $0.25 \mathrm{sec}$ : the ratio is $34 \%$.

- From $0.25 \mathrm{sec}$ to $1 \mathrm{sec}$ : the ratio is $35 \%$.

- From $1 \mathrm{sec}$ to $1.4 \mathrm{sec}$ : the ratio is $27 \%$.

- From $1.4 \mathrm{sec}$ to $3 \mathrm{sec}$ : the ratio is $20 \%$.

So, when using PI controller, the speed and torque have some ripples.

\subsection{Using sliding mode Controller}

For the speed shown in figure 5.8, the rise time is $1.2539 \mathrm{sec}$ and the settling time is $1.389 \mathrm{sec}$. The maximum overshoot is $6 \mathrm{rpm}$ which is very small and less than $2 \%$. The peak time is $0.283 \mathrm{sec}$, and the delay time is $1.055 \mathrm{sec}$. For the torque shown in figure 5.9, the ratio of ripples varies as follows:

- From 0 sec to $0.25 \mathrm{sec}$ : the ratio is $30 \%$.

- From $0.25 \mathrm{sec}$ to $1 \mathrm{sec}$ : the ratio is $40 \%$

- From $1 \mathrm{sec}$ to $1.4 \mathrm{sec}$ : the ratio is $32 \%$.

- From $1.4 \mathrm{sec}$ to $3 \mathrm{sec}$ : the ratio is $40 \%$.

So, when using sliding mode controller, the speed has some ripples with magnitude less than the PI controller, but the torque ripples are still high. These results are summarized in Table 1 and Table 2.

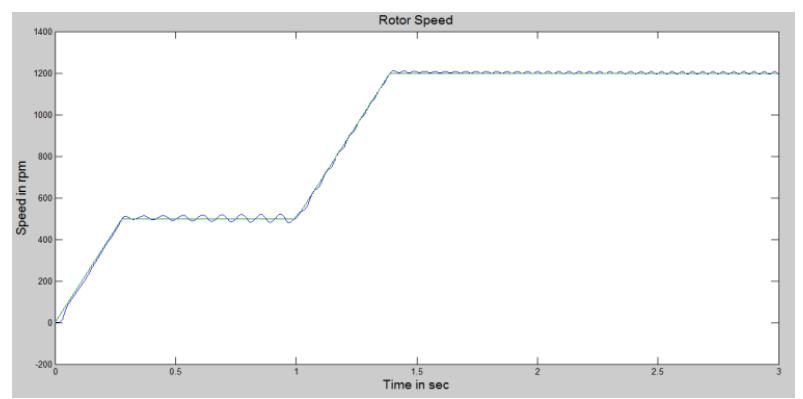

Fig. 2: Reference vs. actual speed using PI controller.

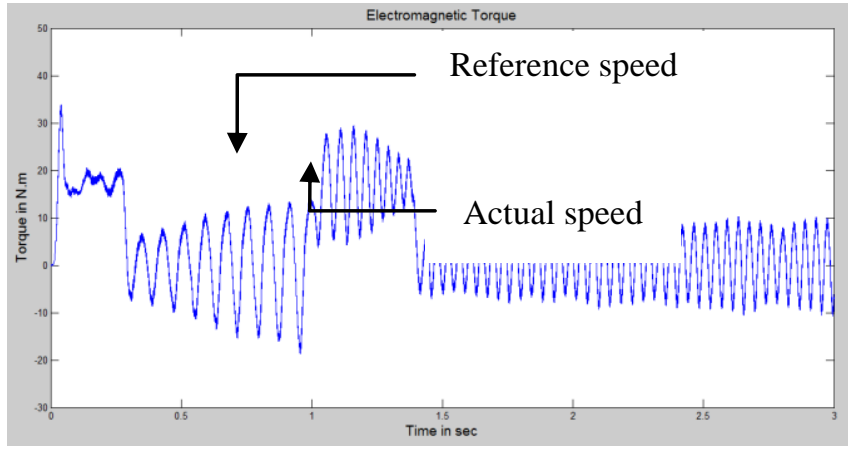

Fig. 3: Electromagnetic torque using PI controller.

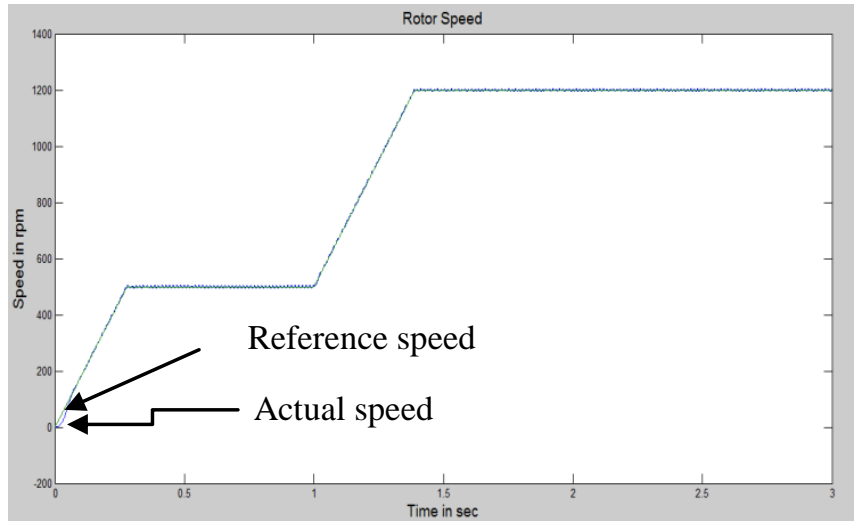

Fig. 4: Reference vs. actual speed using SMC. 


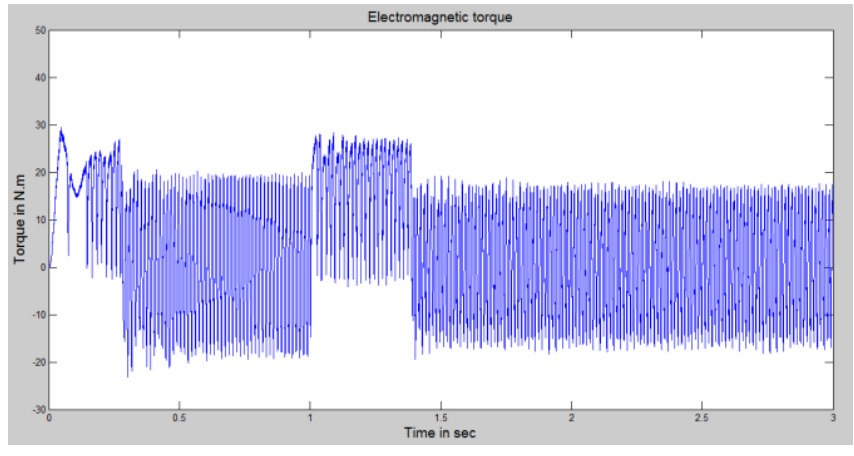

Fig. 5: Electromagnetic torque using SMC.

\section{COMPARATIVE ANALYSIS}

In this section, a comparison with A R. Arulmozhiyaly and K. Baskaran [17] using different speeds and load torques is performed. Figure 6 shows the speed using the proposed sliding mode controller at speed $1000 \mathrm{rpm}$ and no load. Figure 7 shows the speed using the proposed sliding mode controller at reference speed of $1000 \mathrm{rpm}$ and load of 5 N.m. Figure 8 shows the speed using the proposed sliding mode controller at reference speed of $1200 \mathrm{rpm}$ and no load. Figure 9 shows the speed using the proposed sliding mode controller at reference speed of $1200 \mathrm{rpm}$ and load of 5 N.m.

From the results shown in the last figures, it is clear that the sliding mode controller gives better response and lower overshoot than PI and fuzzy PI controllers. Table 3 shows the settling time using the proposed sliding mode controller and fuzzy PI controllers. The results are approximately the same.

Table 1: Comparison of speed between PI, PID, and SMC

\begin{tabular}{|c||c||c||}
\hline \hline Speed & PI & Sliding mode \\
\hline \hline Rise time (s) & 1.2526 & 1.2539 \\
\hline Settling time (s) & 1.405 & 1.389 \\
\hline $\begin{array}{c}\text { Maximum overshoot } \\
\text { (rpm) }\end{array}$ & 21 & 6 \\
\hline Peak time (s) & 0.935 & 0.283 \\
\hline Delay time (s) & 1.06 & 1.055 \\
\hline
\end{tabular}

Table 2: Comparison of torque between PI, PID, and SMC

\begin{tabular}{|c|c|c|c|}
\hline \multicolumn{2}{|c|}{ Torque } & PI & Sliding Mode \\
\hline \multirow{4}{*}{$\begin{array}{c}\text { Ratio } \\
\text { of } \\
\text { ripples } \\
\%\end{array}$} & $0-0.25$ & 34 & 30 \\
\hline & $0.25-1$ & 35 & 40 \\
\hline & $1-1.4$ & 27 & 32 \\
\hline & $1.4-3$ & 20 & 40 \\
\hline
\end{tabular}

Table 3: Comparison of settling time in sec between fuzzy PI and SMC.

\begin{tabular}{|l||c||c||}
\hline \multicolumn{1}{|c||}{ Load Condition } & $\begin{array}{c}\text { Fuzzy PI } \\
{[17]}\end{array}$ & Sliding mode \\
\hline \hline 1000 rpm with no load & 0.7 & 0.71 \\
\hline 1000 rpm with load & 0.79 & 0.71 \\
\hline 1200 rpm with no load & 0.79 & 0.858 \\
\hline 1200 rpm with load & 0.85 & 0.85 \\
\hline
\end{tabular}

\section{CONCLUSION}

This paper proposed a sliding mode controller design to control the speed of an induction motor fed by three phase voltage source inverter based on space vector pulse width modulation technique. The proposed scheme enabled us to adjust the speed of the motor by controlling the frequency and amplitude of the stator voltage; the ratio of the stator voltage to the frequency should be kept constant. It is introduced to maintain a constant speed to when the load varies. Simulation results showed the validation of the proposed scheme. As a conclusion, the sliding mode controller gives lower overshoot than PI and fuzzy PI controllers. As a future work, more analysis is needed to face the sliding mode controller torque ripples which are not completely eliminated.

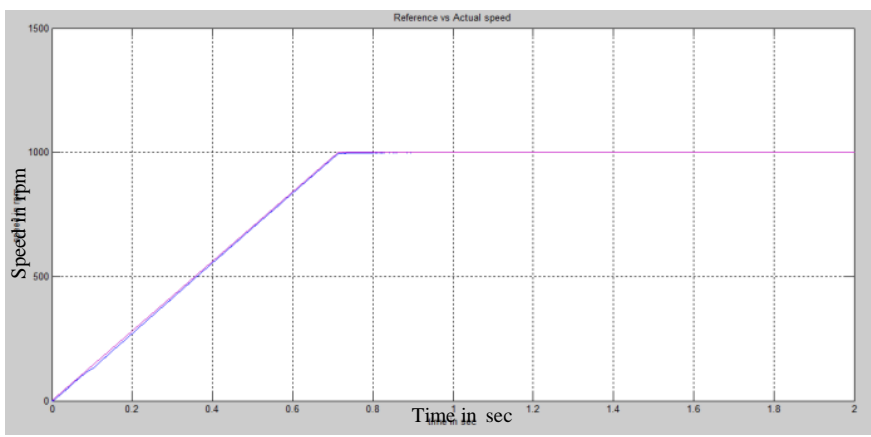

Fig. 6: Reference vs. actual speed using SMC at speed $1000 \mathrm{rpm}$ and no load.

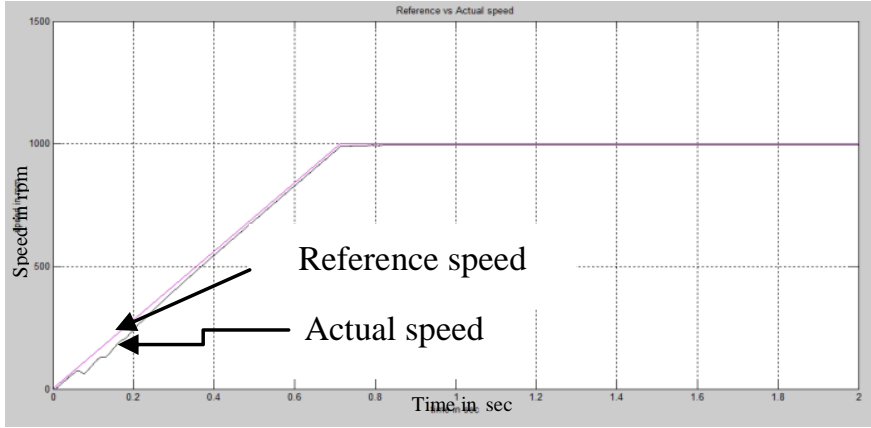

Fig. 7: Reference vs. actual speed using SMC at Speed of 1000 rpm with load of 5 N.m.

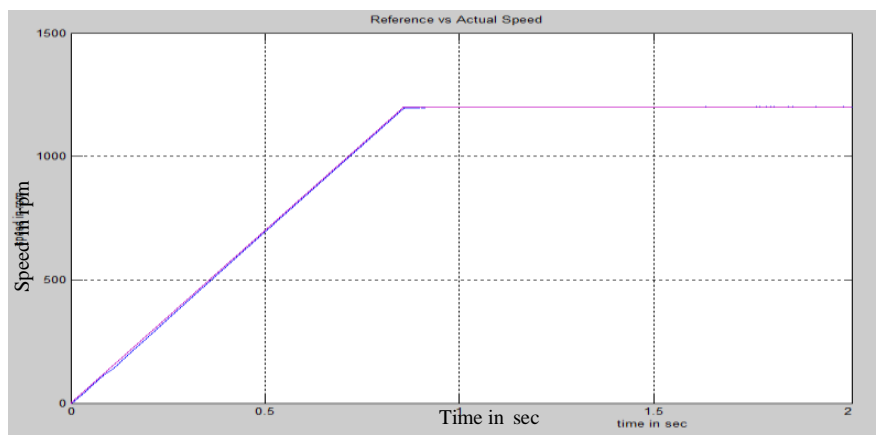

Fig. 8: Reference vs. actual speed using SMC at Speed of 1200 rpm with no load. 


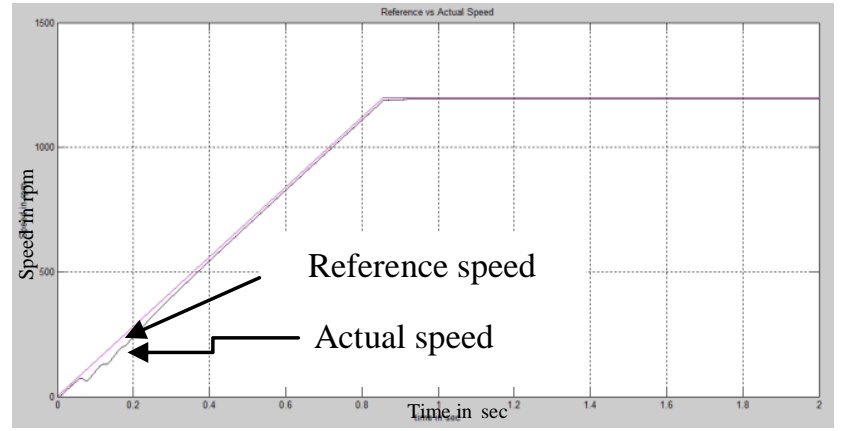

Fig. 9: Reference vs. actual speed using SMC at Speed of 1200 rpm with load of 5 N.m.

\section{REFERENCES}

[1] Bimal K. Bose, "Modern Power Electronics and AC Drives," Pearson education, Prentice Hall; 1 edition, 2001

[2] Werner Leonhard, "Control of Electrical Drives," Springer Verlag, 3nd edition 2001.

[3] S. K. Sul and T. A. Lipo, "Field oriented control of an induction machine in a high frequency link power system", IEEE Transactions on Power Electronics, vol.5, no.4, pp.436-445, 1990.

[4] I. Takahashi and T. Noguchi, "A new quick-response and high-efficiency control strategy of an induction motor", IEEE Transactions on Industry Applications, vol.A-22, no.5, pp.820-827, 1986.

[5] J.-K. Kang and S. K. Sul, "New direct torque control of induction motor for minimum torque ripple and constant switching frequency", IEEE Transactions on Industry Applications, vol.35, no.5, pp.1076-1082, 1999.

[6] D. Casadei, G. Serra and A. Tani, "Implementation of a direct torque control algorithm for induction motors based on discrete space vector modulation", IEEE Transactions on Power Electronics, vol.15, no.4, pp.769$777,2000$.

[7] N. R. N. Idris and A. H. M. Yatim, "Direct torque control of induction machines with constant switching frequency and reduced torque ripple", IEEE Transactions on Industrial Electronics, vol.51, no.4, pp.758-767, 2004.

[8] C. Lascu, I. Boldea and F. Blaabjerg, "A modified direct torque control for induction motor sensorless drive",
IEEE Transactions on Industry Applications, vol.36, no.1, pp.122-130, 2000.

[9] Y.-S. Lai and J.-H. Chen, "A new approach to direct torque control of induction motor drives for constant inverter switching frequency and torque ripple reduction", IEEE Transactions on Energy Conversion, vol.16, no.3, pp.220-227, 2001.

[10] D. Sun, J. G. Zhu and Y. K. He, "A space vector modulation direct torque control for permanent magnet synchronous motor drive systems", Proc. of the Fifth International Conference on Power Electronics and Drive Systems, vol.1, pp.692-697, 2003.

[11] Wei-Feng Zhang and Yue-Hui Yu, "Comparison of Three SVPWM Strategies," Journal of electronic science and technology of china, No.3, pp. 283-287, Sep. 2007.

[12] Iqbal.A, "Analysis of space vector pulse width modulation for a five phase voltage source inverter," IE (I) journal-EL, Vol. 89, Issue 3, pp.8-15, Sep. 2008.

[13] Mondal, S.K.; Bose, B.K.; Oleschuk, V.; Pinto, J.O.P "Space vector pulse width modulation of three-level inverter extending operation into overmodulation region," IEEE Transactions on Power Electronics, Vol. 18, Issue 2, pp. 604 - 611, Mar. 2003.

[14] J.-J. E. Slotine and W. Li, "Applied nonlinear control", Englewood Cliffs, Prentice-Hall, New Jersey,1991.

[15] X. Liu and W. Wang, "High order sliding mode and its application on the tracking control of piezoelectric systems", International Journal of Innovative Computing, Information and Control, vol.4, no.3, pp.697-704, 2008.

[16] X.-Z. Zhong, H.-L. Xing and K. Fujimoto, "Sliding mode variable structure control for uncertain stochastic systems", International Journal of Innovative Computing, Information and Control, vol.3, no.2, pp.397-406, 2007.

[17] R. Arulmozhiyaly and K. Baskaran, "Implementation of a Fuzzy PI Controller for Speed Control of Induction Motors Using FPGA", Journal of Power Electronics, Vol. 10, No. 1, January 2010.

[18] Kanungo Barada Mohanty, "Sensorless Sliding Mode Control of Induction Motor Drives" , Electrical Engineering Department, National Institute of Technology, Rourkela-769008, India, May 18, 2009. 